\title{
O ETERNO EXERCÍCIO EXPERIMENTAL...
}

\author{
Jeanine Toledo
}

Fico pensando qual o papel do artista na contemporaneidade, isto é, qual o seu comportamento perante as exigências do mundo atual?

O posicionamento político que o artista deve ter na sociedade, remonta velhos tempos. No passado havia as demandas da aristocracia ou da igreja e os artistas tinham que se moldar ou se rebelar às convenções da época. Havia sempre o 'mecenas' a ditar os caminhos que queriam e as suas encomendas.

Penso que talvez o papel do artista, mesmo a despeito de entrar no circuito e tudo o que o envolve, seja conseguir falar de coisas prementes relativas ao universo atual, como diz Aracy Amaral (2016)" "se o artista é a antena do mundo, como dizia Pound com outras palavras, deveríamos poder ver mais, através da arte e nós não estamos vendo isto".

Sou alagoana e fui morar no Recife para fazer faculdade no fim dos anos de 1970. Queria ter feito Belas Artes à época, mas a escola havia fechado. Então, como sempre gostei de desenhar, achei que iria gostar de criar identidades e acabei me formando em Programação Visual.

Depois que me formei senti que Programação Visual não era bem o que me satisfazia, como eu gostava muito de pintar, senti a necessidade de entrar a fundo na pintura. Na pintura eu me encontrava, ela me desafiava a cada dia e era uma relação de paixão e diálogo entre o quadro e eu. Nela eu me sentia realizada.

Meu trabalho de pintura seguia uma linha expressionista alemã. Nessa época no Brasil, principalmente no eixo Sudeste (São Paulo e Rio de Janeiro) havia o movimento da retomada da pintura, um movimento que culminou na exposição antológica Como vai você geração 80?, Rio de Janeiro, 1984. Era uma exposição que queria dar conta não apenas da 'volta à pintura', mas também mostrava o que estavam fazendo os artistas durante a época da ditadura militar no Brasil. Muitos expoentes dessa mostra permaneceram trabalhando nesse suporte até os dias de hoje, tais como, Luiz Zerbini (1959), Beatriz Milhazes (1960), Leda Catunda (1961) e Cristina Canale (1961). Esse panorama evidenciou que os anos 1980 não foram mera 'volta' e sim um caminho de reaproximação com a imagem. Posta em xeque pela chamada desmaterialização da arte e pelo conceitualismo nas duas décadas anteriores, a imagem voltou a ocupar um lugar de destaque na produção do período.

Nesse tempo em Pernambuco, existia uma verdadeira efervescência nas artes plásticas. O estado sempre teve uma tradição de pintura desde os primórdios com a

\footnotetext{
'Aracy Abreu Amaral, São Paulo, 22 de fevereiro de 1930, é uma crítica e curadora de arte, atualmente é professora titular de História da Arte pela Faculdade de Arquitetura e Urbanismo da USP, também foi diretora da Pinacoteca do Estado de São Paulo (1975-1979) e do Museu de Arte Contemporânea da Universidade de São Paulo (1982-1986) e membro do Comitê Internacional de Premiação do Prince Claus Fund, em Haia na Holanda.
} 
passagem do holandês Frans Post pelo Recife, em 1637. O artista que retratou como ninguém sua paisagem e seus costumes. Seu estilo, predominantemente figurativo, continuou por várias gerações durante séculos. Do Nordeste Brasileiro, o estado de Pernambuco era um dos que mais se destacava por sempre ter sido um celeiro de artistas maravilhosos, como Telles Junior (1851-1914), Vicente do Rego Monteiro (1899-1970), Cícero Dias (1907-2003), Francisco Brennand (1927), João Câmara (1944), Paulo Bruscky (1949), entre tantos outros.

Eu herdei essa tradição. Meu trabalho sempre usou a referência do corpo, ou partes dele, contextualizando a história da arte, a memória, o tempo. Muitas vezes me apropriei de obras ícones da história da arte como temática para as minhas obras e como forma de questionar seus cânones.

Sempre trabalhei sozinha, nunca me inseri em nenhum grupo ou coletivos, coisa que era comum à época. Meu trabalho refletia um pouco esta condição à margem. Com o tempo percebi a necessidade de contextualizar mais o que fazia. A pintura pela pintura não trazia respostas às minhas inquietações. Então, já no final dos anos de 1990, comecei a trabalhar em outros suportes e técnicas e, por conta dessa mudança, também percebi uma necessidade de falar mais sobre o meu trabalho. Isso era uma questão difícil para uma artista que se envolvia com a pintura de uma maneira dionisíaca. Sempre achei que a pintura não devia ser explicada. Pintura é pintura e ela te capta imediatamente ou você passa por ela indiferente. Não é necessário explicações para o fruir. Mas o circuito artístico na contemporaneidade começou a exigir contextos, principalmente enormes textos, verdadeiros compêndios, para explicar os trabalhos artísticos. Algo que sempre achei muito chato.

Das exposições que realizei destaco duas que considero o resultado bastante satisfatório para mim. Foram elas, Uns e Outros e A Lente Turva, respectivamente em 2003 e 2007, na cidade do Recife. Ambas abordaram de maneira muito clara grande parte da minha poética.

Na primeira eu trabalhei inspirada em artistas que fizeram parte de minha 'árvore genealógica'. Ouvi certa vez de um artista brasileiro que admiro muito, o Nelson Leirner (1932), que nós temos uma árvore genealógica artística. Nela, estão contidos os nomes dos artistas que nos influenciaram, com os quais você se identifica ou se identificou durante o seu percurso artístico. Os que são mais próximos de sua poética são os seus pais, irmãos; os que são um pouco mais distantes são os primos e tios. Em Uns e Outros eu elenquei artistas da minha "árvore genealógica». Utilizei suas obras, suas frases, retrabalhando-as no meu próprio contexto. Todas as obras foram criadas em vários suportes e técnicas de acordo com a necessidade, como vídeo, pintura e fotografia.

Na segunda exposição, A Lente Turva, parti de uma pesquisa do papel da mulher durante décadas na história da arte. Isto porque sempre me intrigou a mulher ter tido um papel, durante séculos na história da arte, apenas como Objeto e não o Sujeito da obra. Fiz uma vasta pesquisa para descobrir quais foram as primeiras protagonistas muIheres e como algumas obras ícones, mesmo sendo feitas por homens, tinham a mulher 
retratada em postura ativa e não passiva ${ }^{2}$. Todos os trabalhos da mostra basicamente mostravam o meu próprio protagonismo como Sujeito da obra, a artista que revisitava a história da arte fazendo uma releitura de obras ícones que tinham a mulher como Objeto. Foi uma exposição que me deu enorme prazer em realizá-la, desde as pesquisas, até o resultado final. Entendi que o artista pode e deve criar coisas belas baseadas em conceitos ou questões que são preponderantes e que nos cercam.

Depois de ter me permitido enveredar por outros suportes e materiais, também pude ver campos expandidos na minha própria obra. Descobri que, apesar de compêndios, textos e explicações diversas, o que importa realmente é a potência da obra que fala por si. E descobri a liberdade de criar sem amarras. Talvez seja isso a que se referia Mário Pedrosa ${ }^{3}$ quando falou que a "arte é o exercício experimental da liberdade" (Freitas, 2015) ${ }^{4}$.

\section{REFERÊNCIAS BIBLIOGRÁFICAS}

Amaral, A. (2016, 27 de setembro). $32^{\text {a }}$ Bienal de São Paulo: qual arte contemporânea? Jornal O Estado de S. Paulo. Retirado de http://cultura.estadao.com.br/noticias/ artes,32-bienal-qual-arte-contemporanea, 10000078365

Freitas (2015, 11 de abril). Novas edições de obras de Mário Pedrosa reúnem cinco décadas de atividade crítica. Coletâneas de ensaios sobre arte e arquitetura resgatam atuação do intelectual pernambucano. Jornal O Globo. Retirado de https://oglobo.globo.com/cultura/livros/novas-edicoes-de-obras-de-mariopedrosa-reunem-cinco-decadas-de-atividade-critica-15836854\#ixzz4iDixcYMp

\section{NOTA BIOGRÁFICA}

Jeanine Lima Toledo (Maceió/AL, 1962) forma-se em comunicação visual pela UFPE, Recife, em 1983. Seu trabalho volta-se para a pintura e a escultura, com destaque para a representação de partes do corpo humano. Sem desprezar a produção artesanal, também contempla questões conceituais em seus trabalhos. A partir da apropriação de uma frase de Waltercio Caldas "O que é arte? Arte é isto?" dá novo direcionamento a sua pesquisa artística, que ainda remete ao corpo porém reflete e questiona a natureza da arte atual.

E-mail: jeanine.toledo@gmail.com

\footnotetext{
${ }^{2}$ Descobri também, por essa época, a primeira protagonista feminina na pintura, que foi a maravilhosa Artemisia Gentileschi. Uma artista do séc. 17, cujo talento pode ser comprovado pelo fato de ter sido a primeira mulher aceite na Academia de Belas Artes de Florença, na Itália, a mesma pela qual passou Michelangelo. Artemisia sofreu com a indiferença e a rejeição do mundo artístico de sua época por ser mulher, e passou pela humilhação de ver a autoria de seus quadros atribuída a seu pai e outros artistas masculinos. A artista já tinha começado a pintar figuras femininas fortes, inspirada tanto pela Bíblia quanto pela mitologia, mas com uma nova perspectiva: a do sujeito da obra. Demorou muito para que seu valor artístico fosse reconhecido. E apenas na década de 1970 Artemisia se tornou um símbolo do feminismo

3 Mario Pedrosa, Timbaúba/PE, 25 de abril de 1901- 11 de novembro de 1981. Crítico de arte, jornalista, professor.

${ }^{4}$ Em entrevista concedida por email ao jornalista Guilherme Freitas, Lorenzo Mammì, crítico de arte e professor de Filosofia na USP, à respeito desse exercício, nos diz que: "na década de 1960, Pedrosa percebeu que uma leitura exclusivamente formal da obra de arte não dava conta da produção recente. Já não era questão apenas de linguagens, mas de comportamentos artísticos. Ele, que sempre defendeu uma arte experimental, lançou mão então dessa fórmula".
} 
Av. Flor de Santana, 139 apt 401 - Parnamirim, Recife, PE CEP: 52060290, Brasil

* Submetido: 02/04/2017

* Aceite em: 01/05/2017 